\title{
Racial and Ethnic Disparities in Access to Care during the Early Years of Affordable Care Act Implementation in California
}

\author{
Shana Alex Charles $^{1}$ and Archana J. McEligot ${ }^{1}$ \\ ${ }^{1}$ California State University, Fullerton, Department of Health Science
}

\begin{abstract}
Background and Purpose: Following the Affordable Care Act (ACA) health insurance expansions, this study asks: did racial/ethnic group disparities in access to care remain? And specifically, did Latinos experience worse access to care after the ACA expansions compared to other racial/ethnic groups? Methods: Dataset: 2015 California Health Interview Survey ( $n=21,034 ; N=29,083,000)$. Participants: Adults, ages 18 and older, in California. Analyses: Bivariate chi-square tests and logistic multivariate regressions, including stratification by insurance. Results: Bivariate tests showed associations between racial/ethnic group and access to care. Latinos had lowest rates of having a usual source of care among uninsured (49.5\%) and job-based coverage (85.2\%). One-fifth of uninsured non-Latino whites (21\%) report foregoing needed care. In the multivariate models, non-Latino whites had significantly higher odds of having a usual source of care $(\mathrm{OR}=1.32$; $\mathrm{p}<0.05)$, but also of foregoing needed care $(\mathrm{OR}=1.43$; $\mathrm{p}<0.05$ ), than Latinos. Asian Americans had significantly lower odds of visiting a doctor in the past year $(\mathrm{OR}=0.65 ; \mathrm{p}<0.05)$ than Latino adults. Conclusion: Following the ACA, disparities among racial/ethnic groups have become more complex. While Latino adults still have lower rates of having a usual source of care, Asian American adults have low rates of visiting a doctor, and non-Latino whites have high rates of foregoing needed care. Further research into the causes of difficulties in accessing care is needed, as health insurance expansions did not create health equity in solving access to care problems.

(c) 2018 Californian Journal of Health Promotion. All rights reserved.
\end{abstract}

\section{Introduction}

The Patient Protection and Affordable Care Act of 2010 (ACA) fueled substantial growth in health insurance enrollment, due to new insurance options available nationwide. Health coverage rates rose due to: 1) young adults under age 26 gaining dependent private coverage (implemented in 2010), 2) expansion of the Medicaid program in 32 states (implemented from 2014 to 2016), and 3) creation of new highly-regulated "marketplaces" in which individuals could purchase coverage directly from insurers, mostly with federal subsidies to offset premium costs (implemented in 2014).(KFF, 2013) By the first quarter of 2016, the gains from these new options combined to drive the nationwide uninsured rate down to a historic low of 10.8\%.(Nekvasil, 2016).

Prior to the enactment of the ACA, it was widely recognized that eradicating racial and ethnic disparities in access to health care was an important goal, as emphasized in the Health People 2010 document issued by the U.S. Department of Health and Human Services. $(\mathrm{H}$. People 2010; Waidman \& Rajan, 2000). Earlier research shows that coverage increased among all racial/ethnic groups, and among all income groups (Buchmueller, Levinson, Levy, \& Wolfe, 2016; Sommers, Gunja, Finegold, \& Musco, 2015; Sommers, Maylone, Blendon, Orav, \& Epstein, 2017). However, the gains have not necessarily materialized equally across diverse populations, leaving residual enrollment and access to care disparities.(Chen, VargasBustamante, Mortensen, \& Ortega, 2016; Hayes, Riley, Radley, \& McCarthy, 2017; Sommers, 2017) An evaluation of the increase in coverage for those aged 26 and under implemented in 2010, using the national Behavioral Risk Factors Surveillance Survey (BRFSS), found that racial and ethnic disparities remained (Hayes et al., 
2017). However, the BRFSS has limited applicability to health insurance questions, as it only asks whether a person has current coverage. Additionally, BRFSS has limited ability to assess access to or utilization of health care once a person has gained coverage.

In California, a state equal to $12 \%$ of the population of the United States, the drop in the uninsured rate from 2013 to 2015 (15.5\% uninsured to $9.5 \%$ uninsured) was significantly higher than the flat rate of uninsurance from 2001-2012 (16.2\% in both years, with insignificant variation around this number over the decade) (Charles et al., 2017). A recent study has provided evidence of the improvements that the Medicaid expansion and the subsidized marketplace in California (called Covered California) enabled. Additionally, gains mirrored the national level and insurance rates improved substantially among all racial/ethnic groups and all income groups (Charles \& Becker, 2016).

California's large and diverse population is wellsuited to examine the diversity in efficacy and effectiveness of the ACA health insurance expansions. Using the most recent data available from California's large population-based survey, the 2015 California Health Interview Survey (CHIS), we studied the impact of the ACA health insurance enrollment growth on access to care (namely having a usual source of care, foregoing needed care, and visits to a doctor in the past 12 months) among the different racial and ethnic groups in the state. Our research questions include: 1) Did the existing racial and ethnic disparities that existed prior to the ACA persist after the ACA health insurance expansions had been implemented? and 2) Do Latinos have the lowest rates of having a usual source of care and visits to a doctor in the past 12 months, and the highest rate of foregoing care, regardless of insurance status?

As the first population-based study investigating ethnic and racial differences impact access to care in the most populous state in the US, this study improves our understanding of the importance of the ACA in increasing health equity. Lessons learned from the successes and challenges of this state can provide important insights for other state legislatures and governors, as well as for changes at the federal level to improve the ACA.

\section{Methods}

\section{Study Design and Sample}

The California Health Interview Survey (CHIS) contains roughly 20,000 households per each annual iteration. Within each household, the survey samples randomly to interview one adult, and if present, one adolescent (ages 12-17) and one child (ages 0-11) who are associated with the selected adult. The adolescent and adult survey are administered directly to the selected respondent, and the child survey is administered to the "most knowledgeable adult" on the child's behalf.

A benefit of CHIS is its ability to capture the diversity of California better than other surveys due to its multilingual administration and oversample of Korean and Vietnamese populations. Languages for 2015 included English, Spanish, Chinese (both Mandarin and Cantonese dialects), Vietnamese, Korean, and Tagalog.(CHIS, 2015) In 2015, CHIS included 21,444 households, for a total of 21,034 adult interviews, 754 adolescent interviews, and 2,157 child interviews.(CHIS, 2015). Adults ages 1864 (a subset of the full CHIS adult population) were included in this study, as children's insurance coverage is largely dependent on parental actions, and nearly $100 \%$ of elderly persons are covered through the federal Medicare program.

As the unweighted sample of CHIS is subject to potential bias and cannot fully capture all populations in California, the CHIS survey team applies numerous methods to ensure that the final weighted data analyses use a population that matches the California Department of Finance population projections, based on the most recent Census, for the state.(CHIS, 2016) The sampling methodology of CHIS incorporates a stratified sample, so that a minimum number of households for all counties (or county groups, for those with very small populations) is captured in the sample. County sample size increases with the proportional size 
of the county in relation to the state population; Los Angeles County has the highest number of households in CHIS, as it represents one-third of California.(CHIS, 2016) Additionally, some sub-populations are oversampled to ensure that are adequately represented, including American Indian and Alaskan Natives and Korean Americans. Finally, once the final sample has been reached, each iteration of the CHIS survey has particular data weights applied, which use age, gender, and household income to inflate the unweighted data to match the projected true population of California.(CHIS, 2015)

\section{Measures}

Racial and Ethnic Group. Racial and ethnic group classification was determined based on Office of Management and Budget protocols, including top-coding of any mention of Latino heritage in the hierarchical variable. Respondents could report multiple racial or ethnic group heritages. The categories included: 1) Latino (weighted $N=10,224,000), 2$ ) NonLatino white (weighted $\mathrm{N}=12,253,000), 3$ ) Non-Latino African American (weighted $\mathrm{N}=$ 1,636,000), 4) Non-Latino Asian American or Native Hawaiian or Other Pacific Islander (weighted $\mathrm{N}=4,130,000$ ), 5) Other or multiple race, including American Indian or Alaskan Native (weighted $\mathrm{N}=840,000$ ).

Insurance Status. The main insurance variable measured coverage at the time of the CHIS interviews, which were administered from January to December 2015. Respondents with any private or public coverage, including military coverage, were counted as insured. People reporting coverage from the Indian Health Service or limited public programs (such as Aid to Infants and Mothers) were considered uninsured. Categories of insurance status included: 1) uninsured, 2) Medicaid, 3) employer-based coverage, 4) individually purchased coverage, and 5) other public coverage. Medicare coverage was included in "other public coverage" along with all combinations of multiple coverage types.

Access to Care. Access to care was measured by three outcomes: 1) any visit to a doctor in the past 12 months (yes/no), 2) foregoing needed care (yes/no), and 3) currently has a usual source of care (yes/no).

Statistical Analyses. This study uses bivariate and multivariate analyses to examine a retrospective, self-reported, population-based survey dataset. Data weights are used to create estimates that are representative of the noninstitutionalized California population, and all analyses were performed using the weighted data. Analyses were performed using STATA version 15.1, with a series of data weights that accounted for the county-level stratification of the CHIS sample. Bivariate analyses used chisquare tests to determine significant differences at the $95 \%$ confidence level.

Three separate multivariate logistic regressions were run, using the access to care variables as the dependent variable. Each logistic regression isolated the impact of racial and ethnic group. Since this data is from the year following the major health insurance expansions from the ACA, the number of people in California with Medi-Cal coverage had greatly increased, and the number of uninsured had decreased. The number of people with job-based coverage stayed statistically flat following the ACA health insurance expansions (9).

Covariates in each of the multivariate logistic regression models included: 1) age group, 2) gender, 3) urban vs. rural residency, 4) education level, 5) work status, 6) citizenship status, and 7) insurance status and type. These factors were controlled in the regression models, isolating the residual impact of racial and ethnic group on the access to care outcomes. Covariates were chosen based on the Andersen Model of Behavioral Health, which classifies factors into predisposing, enabling, and need to conceptualize their impact on access to health care.(Andersen, 2008) Racial/ethnic group is itself a predisposing factor, along with covariates 1-6 above. Covariate 7 (insurance type) represents the main enabling factor. Need factors would have been health status or disease type, but were shown in early data runs to have no impact or too small of a sample size, and so were dropped from the models. 


\section{Results}

Table 1 presents the weighted distributions of the adult population in the 2015 CHIS. These proportions show the racial ethnic diversity of the adult population, with significant populations of all groups, although people who self-reported African American in the state was below 6\%. The largest age group for adults were those between 18-34, and nearly half of all adults had household incomes more than 300\% of the Federal Poverty Level (Table 1).

Table 1

Weighted Distributions of Demographic Characteristics, Ages 18+, California, 2015

\begin{tabular}{|c|c|}
\hline Demographic Variable & $\begin{array}{l}\text { \% of Adult Population } \\
(\mathrm{N}=29,083,000)\end{array}$ \\
\hline \multicolumn{2}{|l|}{ Racial/Ethnic Group } \\
\hline Latino & 35.2 \\
\hline Non-Latino White & 42.1 \\
\hline African American & 5.6 \\
\hline Asian American and Other Pacific Islander (including Native Hawaiian) & 14.2 \\
\hline Other Single or Multiple Racial/Ethnic Group & 2.9 \\
\hline \multicolumn{2}{|l|}{ Age Group } \\
\hline Ages 18-34 & 32.3 \\
\hline Ages 35-49 & 25.5 \\
\hline Ages 50-64 & 24.8 \\
\hline Ages 65+ & 17.4 \\
\hline U.S. Born Citizen & 65.9 \\
\hline Naturalized Citizen & 18.0 \\
\hline Non-citizen & 16.2 \\
\hline \multicolumn{2}{|l|}{ Residency } \\
\hline Rural & 9.9 \\
\hline Urban & 90.1 \\
\hline \multicolumn{2}{|l|}{ Household Income as a Percent of the Federal Poverty Level* } \\
\hline$<100 \%$ FPL & 18.2 \\
\hline $100 \%-199 \%$ FPL & 19.1 \\
\hline $200-299 \%$ FPL & 14.0 \\
\hline $300 \%+F P L$ & 48.7 \\
\hline Female Gender & 51.1 \\
\hline Male Gender & 48.9 \\
\hline \multicolumn{2}{|l|}{ Work Status } \\
\hline Full-Time Employed & 56.5 \\
\hline Part-Time Employed & 9.1 \\
\hline Unemployed, Looking for Work & 4.4 \\
\hline Unemployed, Not Looking for Work & 30.0 \\
\hline \multicolumn{2}{|l|}{ Current Insurance Status and Type } \\
\hline Uninsured & 10.0 \\
\hline Medicare & 19.8 \\
\hline Medicaid & 21.5 \\
\hline Job-Based Coverage & 41.9 \\
\hline Individually Purchased Coverage & 6.8 \\
\hline \multicolumn{2}{|l|}{ Education } \\
\hline Less Than High School & 17.3 \\
\hline High School Diploma & 21.9 \\
\hline Some College & 24.0 \\
\hline College Degree & 23.8 \\
\hline Graduate Degree & 13.0 \\
\hline
\end{tabular}

Source: Author's analysis of the 2015 California Health Interview Survey

Note: Percentages may not add to $100 \%$ due to rounding.

* "Federal Poverty Level" is a standard measurement of income used to determine eligibility for public human services programs, including Medicaid. In 2015, the Federal Poverty Level was $\$ 11,770$ for a single-person household; $\$ 15,930$ for a two-person household; $\$ 20,090$ for a three-person household, etc. 
In unadjusted bivariate analyses, Latino adults in California had the lowest rates of having a usual source of care compared to the other three largest racial and ethnic groups among those who are either uninsured (49.5\%) or with jobbased coverage (85.2\%; Figure 1). However, the rate of having a usual source of care among nonLatino Asian Americans with job-based coverage (86.4\%) was not statistically significantly different from the rate among
Latinos. Non-Latino Asian Americans with Medicaid (called Medi-Cal in California) also had the lowest unadjusted rate of having a usual source of care among all four groups (72.8\%). People without insurance had the lowest rates of having a usual source of care consistently among all racial/ethnic groups, with Medi-Cal enrollees having rates that were significantly higher, and those with job-based coverage having the highest rates (Figure 1).

\section{Figure 1}

Percent Having a Usual Source of Care by Current Insurance and Racial/Ethnic Group, Ages 18+,

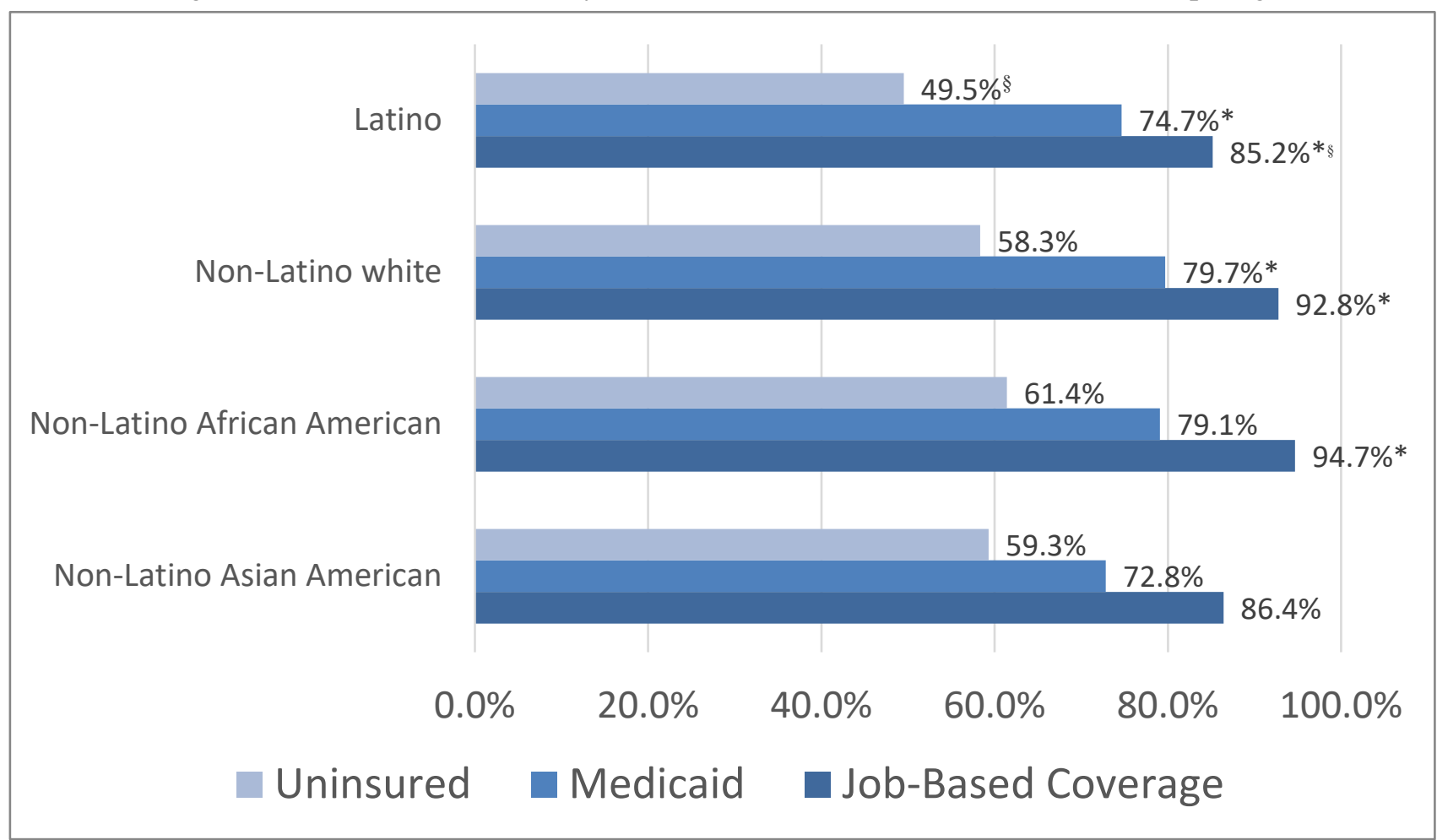

California, 2015

Source: Author's analysis of 2015 California Health Interview Survey

* Significantly different from uninsured rate within same racial/ethnic group.

$\S$ Significantly different from non-Latino white rate within the same insurance status/type.

The unadjusted bivariate analyses for visiting a doctor in the past 12 months revealed a different picture of racial/ethnic group disparity (Figure $2)$. For all insurance statuses and types, nonLatino Asian Americans had the lowest rates of visiting a doctor, ranging from $45.8 \%$ among the uninsured to $80.9 \%$ among those with job-based coverage. Nonetheless, non-Latino whites continued to report the highest rates among all racial/ethnic groups of visiting a doctor in the past year, regardless of insurance status or type. 


\section{Figure 2}

Percent Visiting a Doctor in the Past 12 Months by Current Insurance and Racial/Ethnic Group, Ages 18+, California, 2015

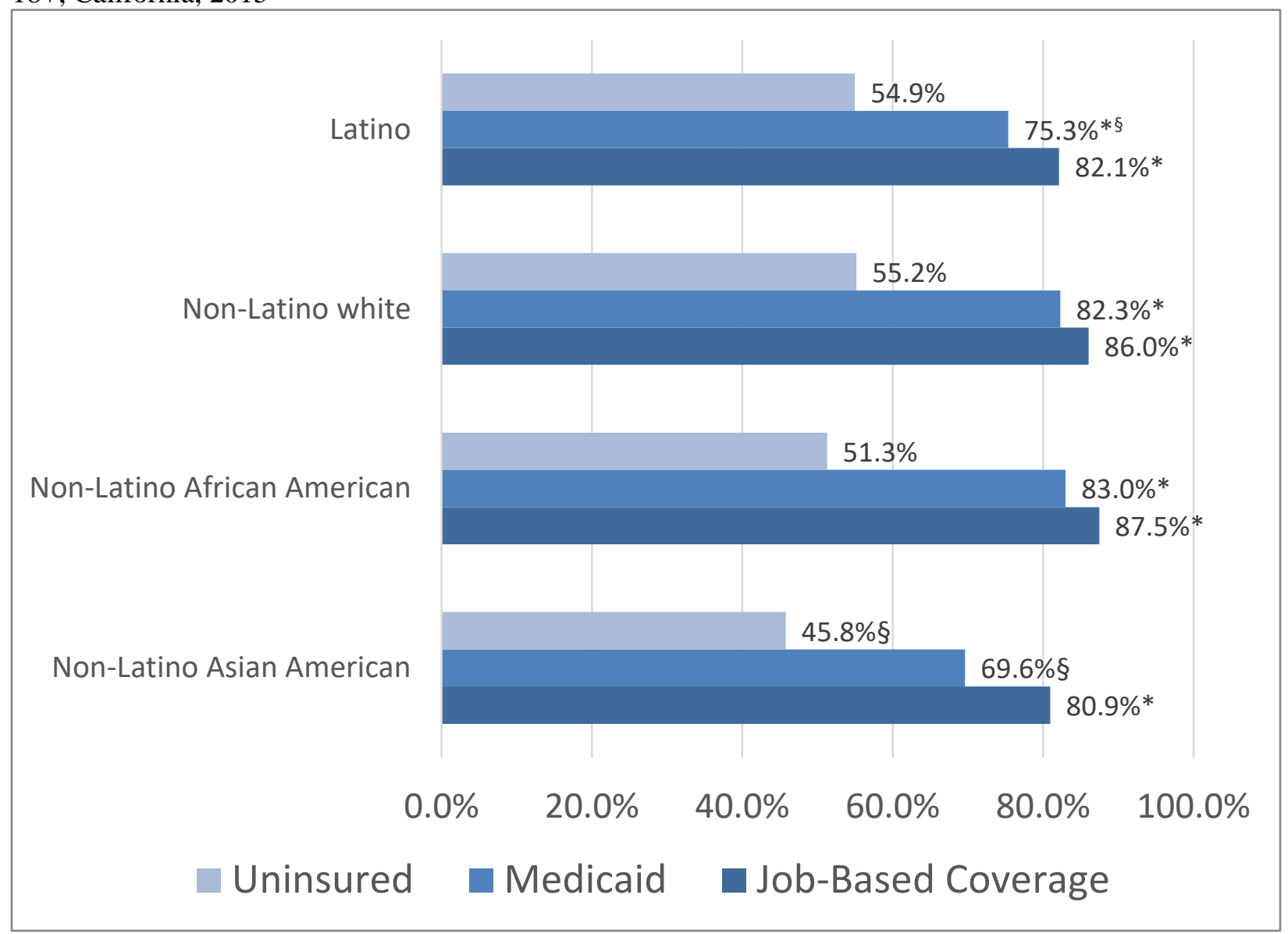

Source: Author's analysis of 2015 California Health Interview Survey

* Significantly different from uninsured rate within same racial/ethnic group.

$\S$ Significantly different from non-Latino white rate within the same insurance status/type.

When examining the unadjusted bivariate results comparing the rates of foregoing needed health care, non-Latino whites again emerge with the highest rates regardless of insurance status or type. This is a negative result, and a higher rate of foregoing care equates to worse access to health care. One-fifth of uninsured non-Latino whites (21\%) report foregoing needed care, the highest rate among all groups (Figure 3), compared to $12 \%$ for Latinos. Among Medi-Cal enrollees, $17.8 \%$ of non-Latino whites report foregoing needed health care, compared to $10.1 \%$ of Latinos. 


\section{Figure 3}

Percent Foregoing Needed Care by Current Insurance and Racial/Ethnic Group, Ages 18+, California, 2015

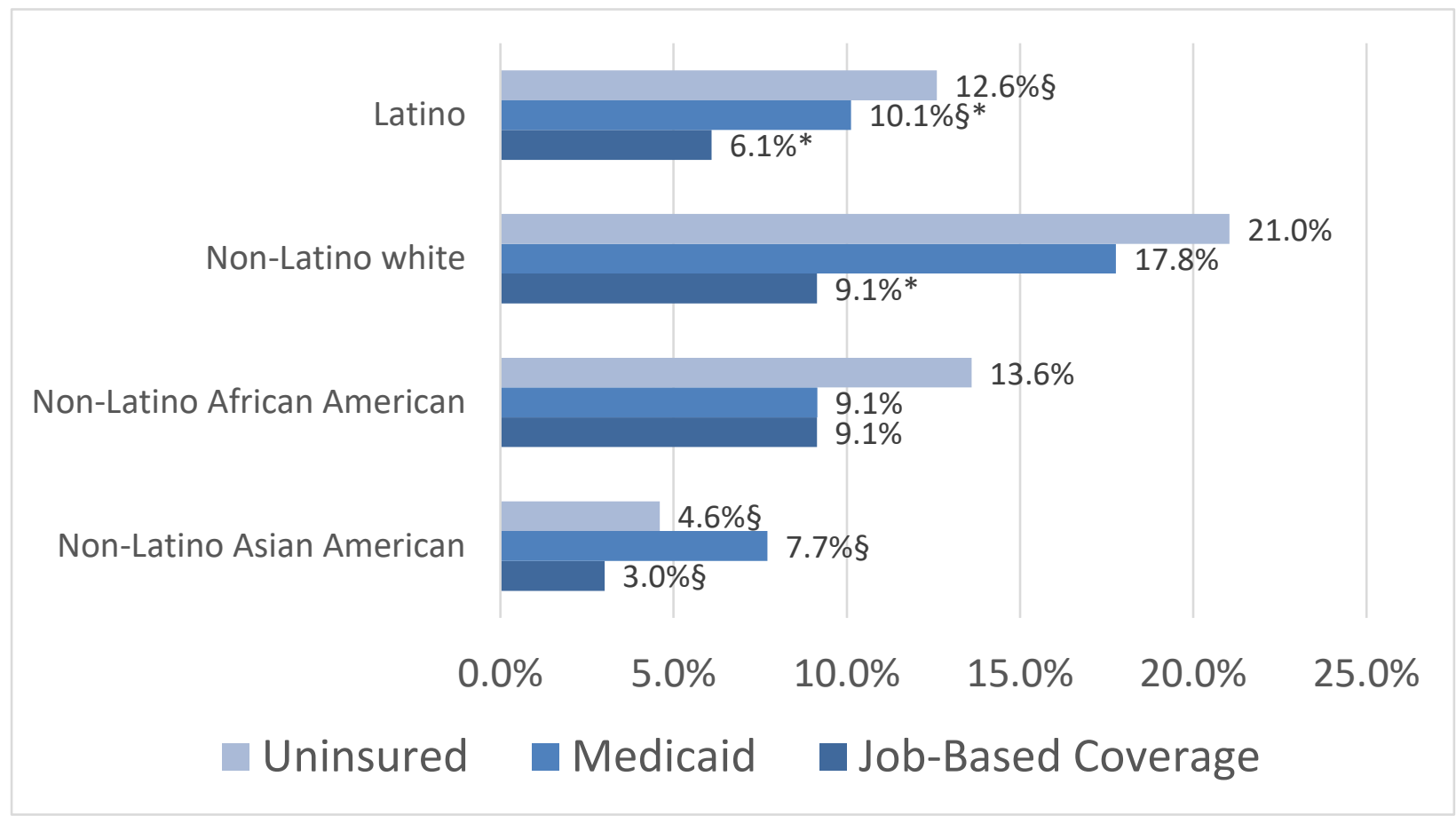

Source: Author's analysis of 2015 California Health Interview Survey

* Significantly different from uninsured rate within same racial/ethnic group.

$\S$ Significantly different from non-Latino white rate within the same insurance status/type.

In the multivariate logistic regression models, non-Latino whites had significantly higher odds of having a usual source of care $(\mathrm{OR}=1.32$; $\mathrm{p}<0.05$; Table 2), but also of foregoing needed care $(\mathrm{OR}=1.43 ; \mathrm{p}<0.05)$, than Latinos. Asian Americans had significantly lower odds of visiting a doctor in the past year $(\mathrm{OR}=0.65$; $\mathrm{p}<0.05)$ than Latino adults.

Table 2

Odds of Having a Usual Source of Care, Visiting a Doctor in the Past 12 Months, or Foregoing Needed Care by Racial and Ethnic Groups. Logistic Regression Analysis with Weighted Data, Ages 18+, California, 2015

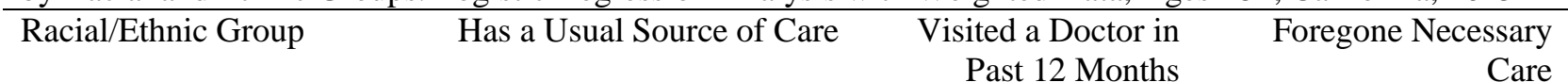

\begin{tabular}{lccr}
\hline Latino & reference group & reference group & reference group \\
\hline Non-Latino white & $1.32[1.05-1.66]^{*}$ & $0.98[0.79-1.20]$ & $1.43[1.06-1.93]^{*}$ \\
\hline African American & $1.30[0.86-1.97]$ & $1.11[0.78-1.59]$ & $0.58[0.34-1.00]^{*}$ \\
\hline Asian American & $0.90[0.64-1.27]$ & $0.65[0.46-0.93]^{*}$ & $0.52[0.25-1.09]$ \\
\hline $\begin{array}{l}\text { Other single or multiple } \\
\text { group }\end{array}$ & $1.01[0.62-1.64]$ & $0.85[0.49-1.47]$ & $1.08[0.61-1.88]$
\end{tabular}

$* \mathrm{p}<0.05$

All models adjusted for age group, gender, current insurance status and type, citizenship status, urban vs. rural living environment, household income as a percent of the federal poverty level, work status, and education.

Source: Author's analysis of 2015 California Health Interview Survey 


\section{Discussion}

Following the ACA health insurance expansions, disproportionalities among racial/ethnic groups have become more complex. This study confirms that Latino adults still have worse rates of having a usual source of care, both in the unadjusted and adjusted models. But in a shift from prior to the ACA, Asian American adults in California have the lowest rates of visiting a doctor, significantly lower than Latino adults. More surprisingly, non-Latino white adults have the highest rates of foregoing needed care, again in both the unadjusted and adjusted models. These results existed despite controlling for household income and insurance status in the models; both of those factors also were significant, with higher income people and people with insurance both having better access to care on all three measures. Therefore, the racial/ethnic group disparities seen here exist even within the same income groups, and within the same insurance groups. Cultural or linguistic barriers may also have separate effects on access to care.

Our findings of Latinos being least likely to have a usual source of care compared to other racial/ethnic groups has been observed in previous studies, particularly those that have focused on the Latino experience in California prior to the ACA health insurance expansions. Also consistent with earlier literature, we found that Asian Americans have the lowest rates of visiting a doctor. Our study, however, found this to be true even when Asian Americans were compared to Latinos, rather than to non-Latino whites.

Last, a majority of the literature has shown that a majority of non-Latino whites seek care when needed, but we surprisingly have shown that non-Latino white adults have the highest rates of foregoing needed care . Our finding is consistent, though, with a study of the National Health Interview Survey (a federal study unrelated to the California Health Interview Survey, although it did provide the model for creating CHIS), which found that after the ACA expansions in 2014, Latinos had significantly lower rates of foregoing care compared to non-
Latino whites. This new pattern has emerged, potentially due to the increased poverty rates among non-Latino whites or increased health care need due to spikes in substance abuse. (NIDA, 2018) Speculation for the cause aside, it's clear that a new pattern is emerging of racial/ethnic disparities, and health care needs are going unmet in our current system.

\section{Limitations}

Limitations to this study include: 1) the reliance of self-reported survey data on respondent recall and bias, 2) the low initial response rate of the CHIS instrument, which has faced similar challenges of all telephone-based surveys nationwide, and 3) the inability to verify respondent report of having a usual source of care or visiting a doctor with medical claims data. The associations found in these models should not be considered to be evidence of a causal effect of racial/ethnic group on any particular outcome, but rather a description of the overall average outcomes experienced by these populations.

\section{Conclusion}

With the mixed results shown by these models, more research into the root causes of difficulties in accessing care beyond obtaining health insurance is needed, as the health insurance expansions under the ACA did not create health equity or solve all access to care problems. Armed with this detailed knowledge, policymakers could target interventions, either linguistically or culturally, to encourage more appropriate use of health care. For instance, to increase the rate of visiting a doctor among Asian Americans, a multi-pronged communications approach could be implemented in counties that have large Asian American populations by county health department officials. Or at the federal level, the knowledge that the non-Latino white population is foregoing care at high rates could inform a nationwide push towards increasing availability of more affordable care. 
Our results show that issues of underinsurance remain even among insured populations, although the largest gap in access to care still remains the gulf between those who have insurance and those who do not. With the recent regulatory decisions from the Trump Administration, these gains have already peaked, with the national rate of uninsurance again rising by the end of 2017. (Gallup, 2018) A rising uninsurance rate will only exacerbate the racial/ethnic disparities found in this study, and will likely have the greatest impact on lowincome communities and communities of color. Under the Trump Administration, the trend is moving away from health equity.

\section{References}

Alcalá, H. E., Chen, J., Langellier, B. A., Roby, D. H., \& Ortega, A. N. (2017). Impact of the Affordable Care Act on health care access and utilization among Latinos. The Journal of the American Board of Family Medicine, 30(1), 52-62.

Andersen, R. M. (2008). National health surveys and the behavioral model of health services use. Medical Care, 46(7), 647-653.

Buchmueller, T. C., Levinson, Z. M., Levy, H. G., \& Wolfe, B. L. (2016). Effect of the Affordable Care Act on racial and ethnic disparities in health insurance coverage. American Journal of Public Health, 106(8), 1416-1421. doi:http://dx.doi.org/10.2105/AJPH.2016.303155

Burgard, S. A., \& Hawkins, J. M. (2014). Race/ethnicity, educational attainment, and foregone health care in the United States in the 2007-2009 recession. American

Journal of Public Health, 104(2), e134-e140.

Charles, S.A., \& Becker, T. (2016). Growth in Medi-Cal in 2016 fueled unprecendented drop in California's uninsured rate. Fact Sheet, UCLA Center for Health Policy Research. Los Angeles, CA.

Charles, S. A., Becker, T., Jacobs, K., Pourat, N., \& Kominski, G. (2017). The State of Health Insurance in California: Findings from the 2014 California Health Interview Survey. Report, UCLA Center for Health Policy Research. Los Angeles, CA.

Chen, J., Vargas-Bustamante, A., Mortensen, K., \& Ortega, A. N. (2016). Racial and ethnic disparities in health care access and utilization under the Affordable Care Act. Medical Care, 54(2), 140.

CHIS Methodology Report Series (2016). Report 2: Data Collection Methods Los Angeles: UCLA Center for Health Policy Research; Available from:

http://healthpolicy.ucla.edu/chis/design/Documents/chis-2015-short-methodology-report-2 datacollection_2016-12-13.pdf

CHIS County Sample Size (2015). Fact Sheet Los Angeles: UCLA Center for Health Policy Research; Available from: http://healthpolicy.ucla.edu/chis/design/Documents/15_county_sample-race.pdf.

Gallup (2018). U.S. Uninsured Rate Steady at 12.2\% in Fourth Quarter of 2017, https://news.gallup.com/poll/225383/uninsured-rate-steady-fourth-quarter-2017.aspx, accessed on 6/19/18.

Hayes, S. L., Riley, P., Radley, D. C., \& McCarthy, D. (2017). Reducing racial and ethnic disparities in access to care: Has the Affordable Care Act made a difference? Issue brief (Commonwealth Fund), 2017, 1.

Hubbell FA, Waitzkin H, Mishra SI, Dombrink J, \& Chavez LR. (1991). Access to medical care for documented and undocumented Latinos in a southern California county. The Western Journal of Medicine, 154, 414-7.

Kaiser Family Foundation (2013). Summary of the Affordable Care Act. Available at: https://www.kff.org/health-reform/fact-sheet/summary-of-the-affordable-care-act/

Kim, Giyeon, Ford, Katy L., Chiriboga, David A., Sorkin, \& Dara H. (2012). Racial and ethnic disparities in healthcare use, delayed care, and management of Diabetes Mellitus in older adults in

California. Journal of the American Geriatrics Society, 60 (12):

http://dx.doi.org/10.1111/jgs.12003 
Ku, L. \& Matani, S. (2001). Left out: Immigrants access to health care and insurance. Health Affairs, 20, 247-56.

Lau, M., Lin, H., \& Flores, G. (2012), Racial/ethnic disparities in health and health care among U.S. adolescents. Health Services Research, 47, 2031-2059. doi:10.1111/j.1475-6773.2012.01394.x

National Institute on Drug Abuse (NIDA) (2018). Opioid Overdose Crisis. Available at: https://www.drugabuse.gov/drugs-abuse/opioids/opioid-overdose-crisis

Nekvasil, N. (2016). Uninsured down since Obamacare; cost, quality still concerns. Retrieved from http://news.gallup.com/poll/195086/uninsured-down-obamacare-cost-quality-concerns.aspx

People, H. (2010). 2000. Healthy People in Healthy Communities: A Systematic Approach to Health Improvement. Report, US Department of Health and Human Services. Washington, DC.

Sommers, B. D. (2017). State Medicaid expansions and mortality, revisited: A cost-benefit analysis. American Journal of Health Economics.

Sommers, B. D., Gunja, M. Z., Finegold, K., \& Musco, T. (2015). Changes in self-reported insurance coverage, access to care, and health under the Affordable Care Act. Journal of the American Medical Association, 314(4), 366-374.

Sommers, B. D., Maylone, B., Blendon, R. J., Orav, E. J., \& Epstein, A. M. (2017). Three-year impacts of the Affordable Care Act: Improved medical care and health among low-income adults. Health Affairs, 10.1377/hlthaff. 2017.0293.

Waidmann, T. A., \& Rajan, S. (2000). Race and ethnic disparities in health care access and utilization: An examination of state variation. Medical Care Research and Review, 57(1_suppl), 55-84.

Weaver, K. E., Rowland, J. H., Bellizzi, K. M., \& Aziz, N. M. (2010). Forgoing medical care because of cost. Cancer, 116(14), 3493-3504.

Author Information

Shana Alex Charles, MPP, PhD

California State University, Fullerton, Department of Health

Science

KHS 237, 800 N State College Blvd

Fullerton, 92831

Phone: (657) 278-8436

Email: scharles@fullerton.edu 